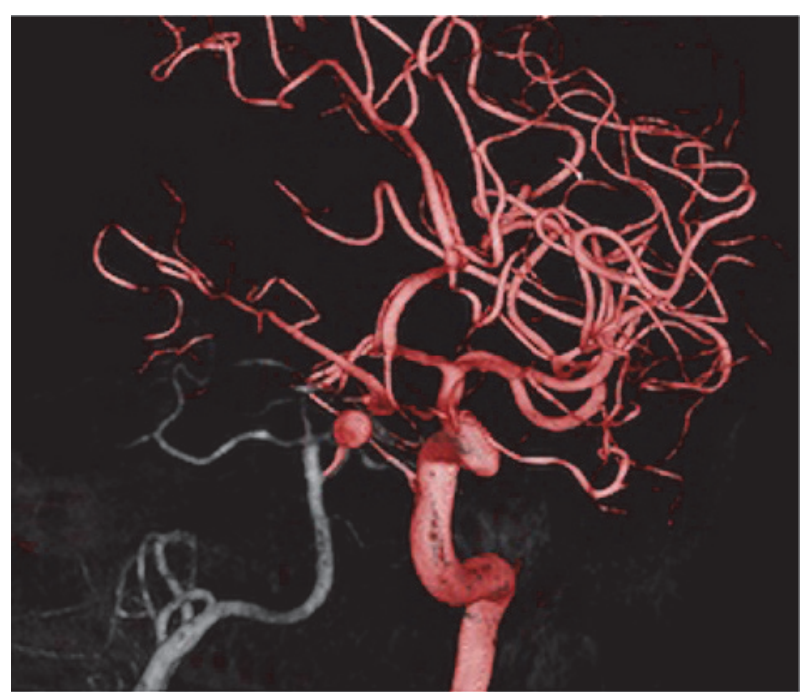

Abstract E-035 Figure 1

Carotid-Basilar anastomoses focusing in anatomic variants of the persistent trigeminal artery.

Results 61-year-old female who presented with quadriparesis after traumatic cervical spinal cord C4-C5 compression; requiring anterior cervical discectomy and fusion. During preoperatory work up, she was found to have a posterior circulation aneurysm in CT angiogram. Patient had a digital subtraction angiography (DSA) that showed a persistent trigeminal artery mid segment aneurysm $5.7 \mathrm{~mm} \times 5.5 \mathrm{~mm}$ in the dominant hemispheric branch and terminate in the SCA territory (Saltzman classification IIIa). After a DSA patient is schedule for endovascular treatment.

Conclusion Persistent trigeminal artery is one of the remnant fetal anastomoses that connect the cavernous segment of carotid artery to the basilar artery. PTA are classified according to angiography by Saltzman in 1959, he reviewed previous reports of PTA along with presenting eight cases and made an angiographic classification dividing in 3 groups. In addition, aneurysms of the PTA are extremely rare in the literature with previous cases reported. This case is unique because there is not report with a 3D rotational DSA of variant PTA aneurysm terminating in the SCA, Saltzman classification type IIIa.

Disclosures A. Ravelo: None. R. Williamson: None.

\section{E-036 NEW IN VITRO AVM MODEL WITH REALISTIC NIDUS FOR SIMULATION AND FLOW ANALYSIS}

${ }^{1} \mathrm{~N}$ Kaneko*, ${ }^{1} \mathrm{H}$ Ullman, ${ }^{1} \mathrm{~F}$ Ali, ${ }^{2} \mathrm{P}$ Berg, ${ }^{1} \mathrm{Y}$ Ooi, ${ }^{1} \mathrm{~S}$ Tateshima, ${ }^{1,3} \mathrm{G}$ Colby, ${ }^{4} \mathrm{Y}$ Komuro, ${ }^{1} \mathrm{P}$ Hu, ${ }^{1} \mathrm{~V}$ Szeder, ${ }^{1,4} \mathrm{M}$ Nour, ${ }^{1} \mathrm{~L}$ Guo, ${ }^{1} \mathrm{~A}$ Chien, ${ }^{1} \mathrm{~F}$ Vinuela, ${ }^{5} \mathrm{~S}$ Nemoto, ${ }^{4} \mathrm{~J}$ Hinman, ${ }^{1} \mathrm{G}$ Duckwiler, ${ }^{1} \mathrm{R}$ Jahan. ${ }^{1}$ Department of Radiological Sciences, UCLA, Los Angeles, CA; ${ }^{2}$ Research Campus STIMULATE, University of Magdeburg, Magdeburg, GERMANY; ${ }^{3}$ Department of Neurosurgery, UCLA, Los Angeles, CA; ${ }^{4}$ Department of Neurology, UCLA, Los Angeles, CA; ${ }^{5}$ Kanto Rosai Hospital, Kawasaki, JAPAN

\subsection{6/neurintsurg-2020-SNIS.72}

Background In vitro vascular models for brain aneurysms and acute stroke have been used for training, simulation and research purpose. However, the use of realistic in vitro models for arteriovenous malformation (AVM) have not been reported. Current in vitro AVM models analyzing the efficacy of embolic materials or flow conditions are limited due to a lack of realistic anatomical and dynamic features of complex nidus.

Materials and Methods 3D AVM nidus images were extracted and segmented from 3D rotational angiography from a patient. Additional artificial feeders and drainers were attached to the AVM nidus. The inner vascular mold was printed using a plastic 3D printer. The inner mold was coated with silicone and then removed with acetone, leaving a hollow AVM model. Injections of liuid embolic material and 4D flow MRI were performed using the 3D in vitro AVM model. Computational fluid dynamics (CFD) analysis was also performed to compare the flow volume and velocity to 4D flow MRI

Results The created in vitro AVM models had realistic representation of nidus vasculature and complexity derived from patients. The injection of liquid embolic material performed in this model replicated real-life treatment conditions. The plug and push technique was successfully simulated to penetratreliquid embolic material into the AVM nidus. The flow data from 4D flow MRI were comparable to CFD analysis.

Conclusions An in vitro human brain AVM model with realistic complexities of nidus was successfully manufactured using $3 \mathrm{D}$ printing technology. The model demonstrated realistic pliability during the liquid embolic material injection and also feasibility of flow analysis. This in vitro AVM model may represent a valuable tool for simulation, flow research and development of new materials or technique.

Disclosures N. Kaneko: None. H. Ullman: None. F. Ali: None. P. Berg: 1; C; German Research Foundation, Federal Ministry of Education and Research within the Forschungscampus STIMULATE. Y. Ooi: None. S. Tateshima: 2; C; Cerenovus, Medtronic, Stryker. G. Colby: 2; C; Medtronic, Microvention, Stryker. Y. Komuro: None. P. Hu: None. V. Szeder: None. M. Nour: None. L. Guo: None. A. Chien: None. F. Vinuela: None. S. Nemoto: None. J. Hinman: None. G. Duckwiler: 1; C; Tarsadia Foundation. 2; C; Medtronic. R. Jahan: None.

\section{E-037 ROBOTIC TRANSCRANIAL DOPPLER USE ANEURYSMAL SUBARACHNOID HEMORRHAGE: A SAFETY AND EFFICACY STUDY}

${ }^{1} \mathrm{~K}$ Clare $*{ }^{2} \mathrm{~A}$ Stein, ${ }^{2} \mathrm{~J}$ Cooper, ${ }^{2} \mathrm{C}$ Gandhi, ${ }^{2} \mathrm{C}$ Bowers, ${ }^{2} \mathrm{C}$ Cole, ${ }^{2} \mathrm{~J}$ Santarelli, ${ }^{2} \mathrm{~J}$ Pisapia, ${ }^{2} \mathrm{~F}$ Al-Mufti. ${ }^{1} \mathrm{New}$ York Medical College, Valhalla, NY; ${ }^{2}$ Neurology and Neurosurgery, Westchester Medical Center, Valhalla, NY

\subsection{6/neurintsurg-2020-SNIS.73}

Introduction/Purpose Transcranial doppler (TCD) is a bedside modality to rapidly assess the presence of vasospasm or stenosis of cerebral arteries. However, manual TCD requires a trained sonographer which may not be available in all healthcare settings. The LUCID TCD system aims to expedite and enhance TCD blood flow measurements through semi-autonomous acquisition. This study aims to evaluate the safety and feasibility of the LUCID TCD system for detection of vasospasm.

Materials and Methods Peak velocities of the middle cerebral arteries (MCA) were measured and a velocity greater than $120 \mathrm{~cm} / \mathrm{s}$ was considered indicative of vasospasm. To determine feasibility, maximal MCA velocities from LUCID TCD were compared to computer tomography angiography, and the Cohen's Kappa value was calculated to gauge the agreement 